\title{
Stress distribution and resistance of lap splices under fatigue loading
}

\author{
Carlos Zanuy, Iván M. Díaz
}

A B S T R A C T

\begin{abstract}
Straight lap splices are employed in reinforced concrete to transfer loads from one steel reinforcing bar to another by bond between the embedding concrete and the two bars along a lapped length. In the last years, some concerns have arisen on the possibility of fatigue of bond-related structural problems, in part due to the very few models available to evaluate the bond fatigue strength. Regarding design standards, some codes for off-shore structures have addressed such a specific topic, by means of a simple S-N formulation. Besides that, recent experimental research has shown that fatigue failures of lap splices can occur because of the poor confinement conditions which result in a small static bond strength leading to high relative stress levels sensitive to fatigue. In the present paper, a mechanical model is proposed to understand the fatigue behaviour of lap splices. The model solves the lap splice problem by taking into account the particular equilibrium, compatibility, constitutive and boundary equations, which produce a different solution than other bond-related problems (anchorages, tension stiffening) in terms of stress distribution along the lapped length. For the local bond-slip behaviour, a cycle-dependent formulation is used for the increase of slip with load cycles and the fatigue failure criterion. The model is able to reproduce the real bond stress distribution, which is nonuniform along the lapped length, and the process of redistribution that takes place with load cycles. It is shown that the redistribution process is responsible for higher fatigue strength than that calculated under the assumption of uniform stress distribution.
\end{abstract}

\section{Introduction}

Fatigue of reinforced concrete may be due to either fatigue of concrete or fracture of the steel reinforcement [1]. Even though most practical experience and research have shown that fatigue of the steel bars is usually the governing failure mode [2,3], increasing concerns regarding possibility of concrete fatigue failures have fostered research on such a topic. Fatigue of steel reinforcement (like other metals and linear materials) can be well predicted by S-N curves, which provide the number of load cycles to failure as a function of the stress oscillation [4]. In case of cycles with different stress range during the service life, the Miner's rule of linear damage accumulation [5] can be applied. Concrete fatigue (compression, shear, bond, etc.) differs significantly from that of the steel due to the nonlinear behaviour of concrete. Before specifically addressing fatigue of bond between concrete and reinforcement for lap splices (which is the focus of this paper), the main aspects of concrete fatigue are firstly introduced for concrete in compression, since it is probably the best known case of the fatigue process of concrete and its structural implications.

In compression, fatigue of concrete has been described as a progressive microcracking mechanism which results at the macroscopic level in the formation of residual strains and stiffness reduction with the number of load cycles until final fatigue failure [6]. Experimental results have shown that the severity of the microcracking deterioration of concrete depends strongly on the stress level, rather than on the stress oscillation as typical of metals $[7,8]$. Because of the complexity of the fatigue mechanics of concrete, S-N-based approaches have been proposed to estimate the fatigue strength as a function of the stress limits of the cyclic load $[9,10]$. Despite such S-N formulations provide an accurate estimate of fatigue strength under constant stress limits, the nonlinearity and stress-dependence of concrete fatigue makes it inappropriate to adopt a linear damage accumulation rule for variable stress limits. It has been shown that the Miner's rule leads to either unsafe or conservative results depending on the stress history [11]. Instead, energy- [12] or strain-based [13] damage accumulation approaches have provided good results, but their direct application to practical cases is not straightforward and most design codes are still based on S-N curves without an explicit consideration of the influence of the nonlinear damage accumulation. The former can result in unrealistic, generally overconservative estimation of the fatigue strength of concrete because fatigue produces a progressive redistribution of stresses whose beneficial influence is not considered [14]. 


\begin{tabular}{|llll|}
\hline \multicolumn{2}{|c|}{ Nomenclature } & $\Phi$ & diameter of steel reinforcement \\
$A_{c}$ & concrete area & $\varepsilon$ & strain \\
$A_{s}$ & steel area & $\rho$ & steel reinforcement ratio \\
$E_{c}$ & concrete modulus of elasticity & $\sigma$ & stress \\
$E_{s}$ & steel modulus of elasticity & $\tau$ & bond stress \\
$N$ & number of load cycles & $\tau_{f}$ & negative frictional bond stress \\
$F$ & load & $\tau_{u}$ & static bond strength \\
$d$ & effective depth & Subscripts \\
$l_{b}$ & anchorage length & & \\
$l_{s}$ & lapped length & 0 & initial \\
$n$ & modular ratio & $c$ & concrete \\
$s$ & relative slip & max & maximum load \\
$s_{1}$ & slip corresponding to $\tau_{u}$ & $\min$ & minimum load \\
$x$ & abscissa & $s$ & steel \\
\hline
\end{tabular}

An overview of the fatigue effect on a reinforced concrete section in bending can be explained with the help of Fig. 1, as described by Zanuy et al. [13]. The positive influence of the capacity for redistribution of stresses is responsible for higher fatigue strength than that estimated by introducing the stress levels of the most initially stressed layer into an S$\mathrm{N}$ curve. The nonlinear stress-dependent deterioration of concrete at different fibers results in a redistribution of stresses from the initially most stressed layers at the top of the section to less damaged layers within the compression zone. Therefore, each concrete layer is actually subjected to cycles of variable stress limits during the fatigue life. Since the most initially stressed top part of the section progressively carries smaller stresses, its fatigue life is longer than the one corresponding to the initial stress levels. So far, the former beneficial effect has been recognized by the Model Code [15] since its 1990 version [9]. The Model Code includes a stress gradient factor which allows reducing the stress level of the most loaded fiber before it can be introduced into the S-N curve. Despite the availability of a simplified approach like the stress gradient factor, most design codes for structural concrete have not even adopted any similar approach so far $[10,16]$. The undesired consequence is that fatigue of concrete might be an issue governing design in some unjustified cases if the design criterion does not account for the real fatigue process of concrete [17].

The above description makes it clear how research can help in understanding the real fatigue sensitivity of concrete and preventing unjustified alarms in normal design cases. For the last years, a similar research need has arisen on fatigue of bond between concrete and ribbed reinforcing bars. First experimental studies from cyclic pull-out tests [18-20] demonstrated that fatigue failure of bond can occur as a result of a damaging process with many similarities with fatigue of concrete in compression: (a) progressive damage of the steel-concrete interface is observable at the macroscopic level by an increase of relative slip with number of load cycles, (b) fatigue of bond depends on the stress level rather than on the stress oscillation.

Bond between concrete and steel reinforcement governs different structural problems: tension chord of a reinforced concrete member in bending, anchorage of steel bars embedded in concrete, lap splices, etc. In such situations, the bond stress distribution along the bonded length might be different from that of a pull-out test, which also recalls the different fatigue response between a reinforced concrete section in bending and a concrete cylinder under constant stress-limit cyclic load. In fact, fatigue loading also produces a redistribution of bond stresses which makes insufficient the employ of S-N curves to evaluate fatigue bond strength. Zanuy et al. [21] have analyzed the recent experimental results from fatigue tests on anchored bars [22,23] and they have confirmed that the nonuniform bond stress distribution along the bonded length plays a decisive role in the fatigue strength of the anchorage. Because the bond stress distribution is not uniform and the fatigue deterioration (cyclic slip increase) depends on the stress level, a redistribution process develops [24] and final fatigue strength is different than that obtained by assuming uniform bond stresses.

There is lack of specific design rules to evaluate fatigue of bond. Only few standards like the Norwegian code for off-shore structures [25] have addressed bond fatigue with S-N-based formulations. The problems of the tension chord and the anchorage under repeated loading have been addressed by the authors' research group in previous works $[21,26]$. In the present paper, the effect of fatigue on lap splices is dealt with, which is possibly the bond-related problem on which more concerns on fatigue have been discussed in the last years [27]. Though real fatigue problems have not been reported, many fatigue failures in laboratory tests have been assigned to bond [28] and there are structural details of off-shore structures, railway bridges or elements supporting rotating machines where significant number of load repetitions are possible.

Because the severity of bond fatigue depends on the relative stress level, the quasi-static bond strength plays a big role (the smaller the bond strength, the higher the relative bond stress level). In turn, the bond strength is influenced by the confinement conditions, which can be provided by the concrete cover, the presence of stirrups, external strengthening or external pressure. Lap splices are the bond-related situation where the confinement conditions are among the poorest, since the concrete cover is limited and external pressure (provided by e.g. the support reactions in anchorage zones) cannot be present. Recent experimental results have shown that fatigue strength of lap splices can be an issue and strengthening methods have been investigated to increase the fatigue strength by improving the confinement [29].

The fatigue strength of lap splices is studied in this paper by a model which is able to reproduce the nonlinear bond stress distribution over the bonded length and the progressive slip increase with number of load cycles. The model allows determining the resistant number of cycles in a realistic way as it is shown from comparison with experimental results.
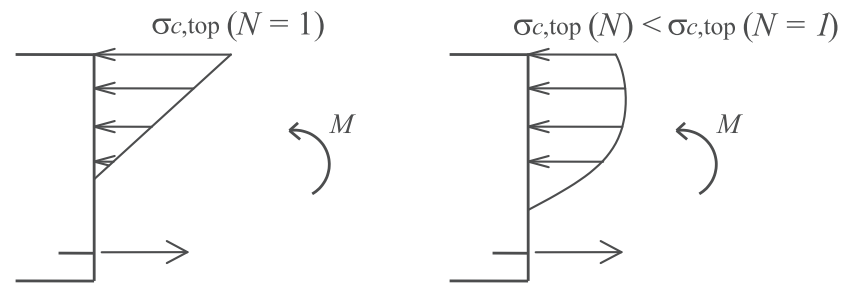

1 st load cycle

After load cycles

Fig. 1. Effect of fatigue loading in a reinforced concrete section in bending. 


\section{Background to fatigue of bond}

The number of cycles to failure from fatigue pull-out tests can be expressed in terms of S-N curves. The configuration of pull-out tests with short bonded length (typically $\leq 5 \Phi$ ) makes it possible to assume that the confinement condition and bond stress distribution are uniform. Therefore, the results of short pull-out tests can be considered as a local material property of the steel-concrete interface. Empirical proposals for S-N curves have been reported by some authors $[19,20]$. The S-N curve of the Norwegian code [25] was simply derived from the S-N curve for concrete in compression by replacing concrete stresses for bond stresses:

$\log N=C_{1} \frac{1-\frac{\tau_{\max }}{\tau_{u}}}{1-\frac{\tau_{\min }}{\tau_{u}}}$

where $C_{1}=12$ for non-submerged structures.

A deeper study of fatigue pull-out tests can be done in terms of the slip increase with load cycles. A representation of the typical evolution of the slip is plotted in Fig. 2, where the three-stage increase reminds the fatigue strain development of concrete under compression. Interestingly, Balazs [18] observed that the third stage, where the slip increases rapidly to failure, begins when the slip has reached the slip corresponding to the peak bond stress of the static envelope $\left(s_{1}\right.$ in Fig. 2). The beginning of the third stage corresponds approximately with $80-90 \%$ of fatigue strength and it will be used here to derive a slipbased S-N curve, as follows.

The slip increase under fatigue cycles with constant stress limits can be described by the following equation [15]:

$s(N)=s_{0} N^{b}$

where $s_{0}$ is the slip reached during the first load cycle, $N$ is the number of load cycles ( $N=1$ corresponds to monotonic static loading) and $b=0.107$ according to Model Code [15]. Sippel [30] observed that $b$ is not constant but dependent on the stress level and Zanuy et al. [31] proposed the following formulation from study of the literature:

$b=\left\{\begin{array}{l}0.107, \tau_{\max } / \tau_{u} \leqslant 0.51 \\ 0.45\left(\frac{\tau_{\max }}{\tau_{u}}\right)^{2.13}, \tau_{\max } / \tau_{u}>0.51\end{array}\right.$

Actually, Eq. (2) only represents the two first stages of the slip increase of Fig. 2. By assuming a failure criterion at the beginning of the third stage, when $s(N)=s_{1}$, the number of cycles to failure yields:

$N=\left(\frac{s_{1}}{s_{0}}\right)^{-1 / b}$

The bond-slip behaviour of the Model Code [15], represented in Fig. 3(a), is here considered as quasi-static envelope, which implies that $\left(s_{1} / s_{0}\right)=\left(\tau_{\max } / \tau_{u}\right)^{1 / \alpha}$, where $\alpha=0.4$. Therefore, the following S-N formulation is obtained from the slip-based failure criteria:

$N=\left(\frac{\tau_{\max }}{\tau_{u}}\right)^{\frac{-1}{\alpha b}}$

Lindorf et al. [32] have also proposed a slip-based failure criterion for bond fatigue. They considered that fatigue failure takes place when the slip has increased $\Delta s=0.1 \mathrm{~mm}$ with respect to the slip reached in the first cycle. Accordingly, an S-N formulation was also derived considering the static bond-slip behaviour of the Model Code [15], as follows [33]:

$N=\left[\frac{\Delta s}{s_{1}\left(\frac{\tau_{\max }+\tau_{\min }}{2 \tau_{u}}\right)^{1 / \alpha}}+1\right]^{\frac{1}{b}}$

A comparison of the proposed S-N model (Eq. (5)) with the other formulations is plotted in Fig. 4. It has to be noted that S-N curves studied in this section are to be considered as a local property. Therefore, a direct application to structural problems is not possible and a specific model for lap splices is necessary.

\section{Bond at structural level}

\subsection{Local bond conditions}

Bond between concrete and reinforcement is responsible for the composite behaviour of reinforced concrete. Structural situations where bond is involved are tension chords, anchorages or lap splices. In general, the local bond conditions along the embedded length are different than those corresponding to short pull-out tests considered in Section 2. The local conditions of an embedded bar can even vary both longitudinal and transversely in complex problems [34]. Like other structural situations, bond-related problems can be solved with the combination of equilibrium, compatibility and constitutive equations, together with the appropriate boundary conditions. The local bond-slip law (Fig. 3(a)) provides the constitutive behaviour of the steel-concrete interface. The parameters governing the local bond-slip behaviour depend on the concrete quality, the geometry of the interface and the confinement conditions. The confinement plays a big role, since it defines the bond failure mode ranging from pull-out by shearing of concrete keys (well-confined condition) to unstable splitting crack propagation (unconfined condition), refer to Fig. 5. Guizani and Challal [35] noted that many structural details are characterized by an intermediate situation referred to as moderately confined condition with a failure driven by stable propagation of a splitting crack.

Many models have been reported to estimate the static bond properties [36]. The Model Code [15] provides the following equation to calculate the local bond strength:

$\tau_{u}=\eta_{2} 6.5\left(\frac{f_{c}}{25}\right)^{0.25}\left(\frac{25}{\Phi}\right)^{0.2}\left[\left(\frac{c_{\min }}{\Phi}\right)^{0.33}\left(\frac{c_{\max }}{\Phi}\right)^{0.1}+k_{m} K_{t r}\right]$

where $\eta_{2}=1.0$ (good bond position) or 0.7 (other bond condition), $c_{\min }$ and $c_{\max }$ are function of the largest and smallest covers of the member, and $k_{m}$ and $K_{t r}$ depend on the confinement provided by transverse reinforcement or stirrups. Bond strength values of around $2.5 f_{c}^{0.5}$ corresponding to well-confined concrete cannot be easily achieved in lap splices (concrete cover larger than $5 \Phi$ or dense confining reinforcement is required). Rather, smaller bond strength corresponding to unconfined or moderately confined condition $\left(0.7-1.5 f_{c}^{0.5}\right)$ has been experimentally obtained $[29,37]$. Therefore, high relative stresses $\left(\tau_{\max } / \tau_{u}\right)$ able to produce fatigue according to Eq. (5) might be expected. Zanuy et al. [21] have verified that bond fatigue is not to be expected in anchored bars under well-confined condition but it could be an issue if the confinement is poor. Lap splices, because of the poor confinement condition, deserve a specific study in order to understand the high fatigue sensitivity that has been reported in previous experimental studies $[29,37]$.
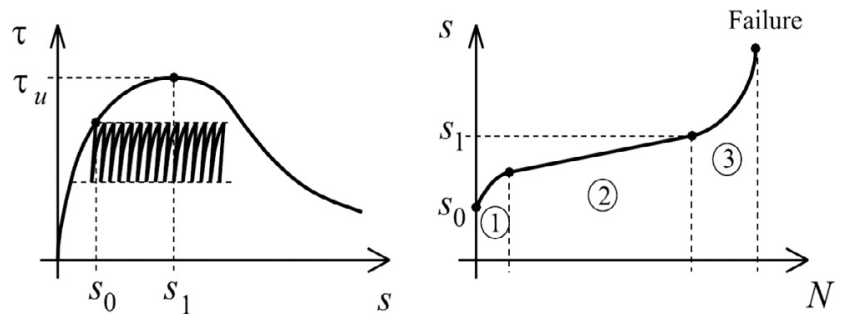

Fig. 2. Schematic representation of slip increase during a fatigue pull-out test. 


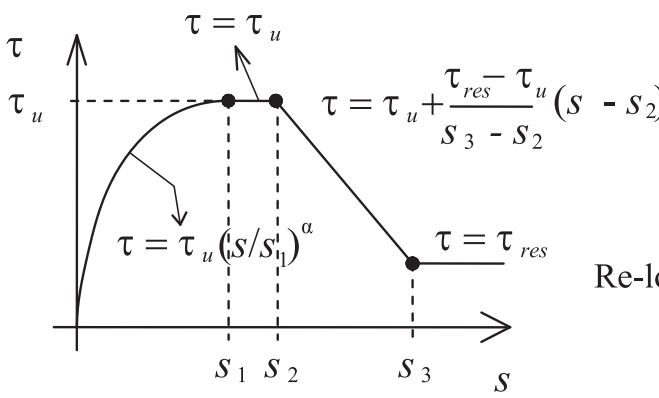

(a)

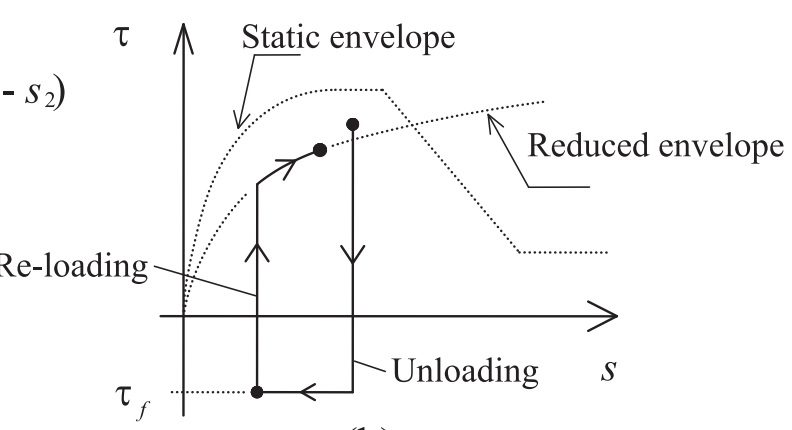

(b)

Fig. 3. (a) Local bond-slip model provided by the Model Code [15]; (b) unloading-reloading behaviour [21].

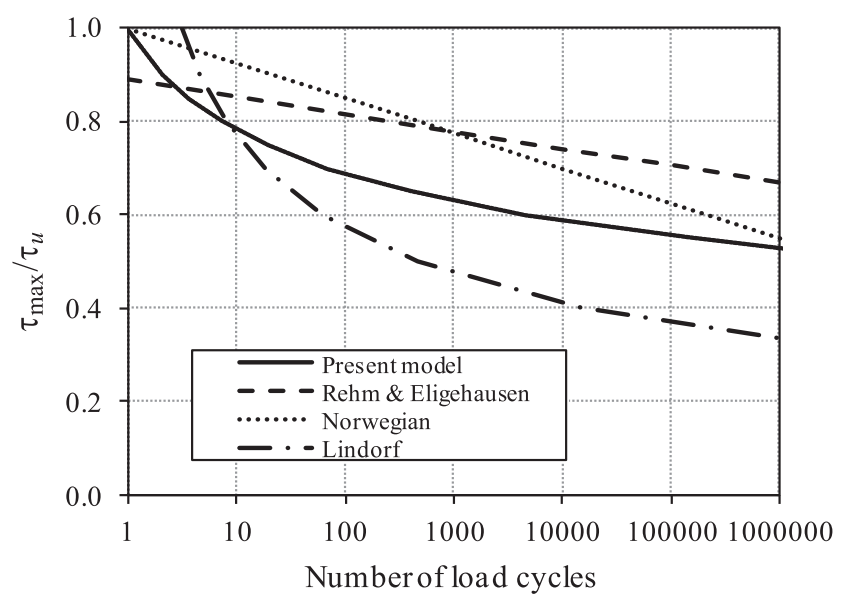

Fig. 4. Comparison of S-N curves for bond fatigue $\left(\tau_{\min } / \tau_{u}=0.1\right)$.

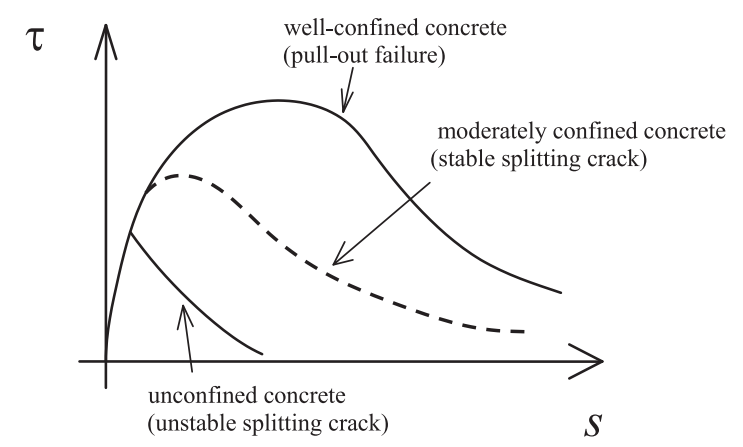

Fig. 5. Bond-slip behaviour as a function of confinement condition.

\subsection{Bond stress distribution of lap splices}

A lap splice is intended to transfer the tensile load carried by an embedded steel bar to a different bar through the bond stresses generated along a lapped distance. A scheme is plotted in Fig. 6(a), where both lapped steel bars have the same diameter $(\Phi)$. The two bars are embedded within a concrete section $A_{c}$ over a lap splice length of $l_{s}$. The external load $(F)$ is fully carried by bar 1 at the left section $(x=0)$ and it has been fully transferred to bar 2 at the right section $\left(x=l_{s}\right)$. The load carried by bar 1 is first transferred to the concrete (bond stress $\tau_{1}$ ) and then from the concrete to bar 2 (bond stress $\tau_{2}$ ). The equilibrium of stresses within a differential portion of the splice is drawn in Fig. 6(b). The equilibrium at the three members (steel bars 1 and 2 and concrete) results in the following equations:

$\frac{d \sigma_{s 1}}{d x}=\tau_{1} \frac{4}{\Phi}$ $\frac{d \sigma_{s 2}}{d x}=\tau_{2} \frac{4}{\Phi}$

$\frac{d \sigma_{c}}{d x}=-\left(\tau_{1}+\tau_{2}\right) \frac{4 \rho}{\Phi}$

where $\rho=A_{s 1} / A_{c}=A_{s 2} / A_{c}$ is the steel reinforcing ratio. The compatibility between concrete and steel bars can be written as:

$\frac{d s_{1}}{d x}=\varepsilon_{s 1}-\varepsilon_{c}$

$\frac{d s_{2}}{d x}=\varepsilon_{s 2}-\varepsilon_{c}$

Under linear elastic behaviour of concrete and steel, the differential equations governing the lap splice can then be derived by introducing Eqs. (8)-(10) into Eqs. (11) and (12) and differentiating once:

$\frac{d^{2} s_{1}}{d x^{2}}=\frac{4}{E_{S} \Phi}\left[\tau_{1}(1+n \rho)+\tau_{2} n \rho\right]$

$\frac{d^{2} S_{2}}{d x^{2}}=\frac{4}{E_{S} \Phi}\left[\tau_{1} n \rho+\tau_{2}(1+n \rho)\right]$

The boundary conditions of the problem are:

$x=0:\left\{\begin{array}{l}\varepsilon_{s 1}=F / E_{S} A_{s 1} \\ \varepsilon_{s 2}=0 \\ \varepsilon_{c}=0\end{array} \Rightarrow\left\{\begin{array}{l}s^{\prime}{ }_{1}(x=0)=\frac{F}{E_{s} A_{s 1}} \\ s^{\prime}{ }_{2}(x=0)=0\end{array}\right.\right.$

$x=l_{s}:\left\{\begin{array}{l}\varepsilon_{s 1}=0 \\ \varepsilon_{s 2}=F / E_{s} A_{s 2} \\ \varepsilon_{c}=0\end{array} \Rightarrow\left\{\begin{array}{l}s^{\prime}{ }_{1}\left(x=l_{s}\right)=0 \\ s^{\prime}{ }_{2}\left(x=l_{s}\right)=\frac{F}{E_{s} A_{s 2}}\end{array}\right.\right.$

The above system of differential equations is nonlinear due to the nonlinear bond-slip behaviour (Fig. 3(a)), which means that a closedform solution cannot be found. Instead, the problem can be solved numerically as schematized in Fig. 7. The splice length $l_{s}$ is divided into $n$ nodes and $n-1$ portions of length $\Delta x=l_{s} /(n-1)$. The equations governing the lap splice are written in incremental form, so that the load $F$ is progressively transferred from bar 1 to bar 2 through concrete. Eq. (15) is imposed at $x=0$, and trial values for the slips $s_{1}$ and $s_{2}$ at $x=0$ are introduced until the solution is found when the stress state at $x=l_{s}$ verifies Eq. (16). The regula-falsi iteration algorithm (secant method) has been used as it provides excellent robustness of the numerical method with very small computing times.

An example of a lap splice of a $16 \mathrm{~mm}$ bar and $l_{s}=20 \Phi$ is solved in Fig. 8. Obviously, stresses and slips of both embedded bars 1 and 2 follow symmetrical distributions with respect to each other. As it can be noted, the bond stress distribution is not uniform along the lapped length. The nonuniformity is more pronounced for smaller load levels. For such small loads (Fig. 8-left), only the zone near the loaded end of each bar slips, while the free end of each lapped bar does not experience any significant slip. As the load level increases (Fig. 8-middle), the 
$\operatorname{Bar} 2, A_{s 2}$

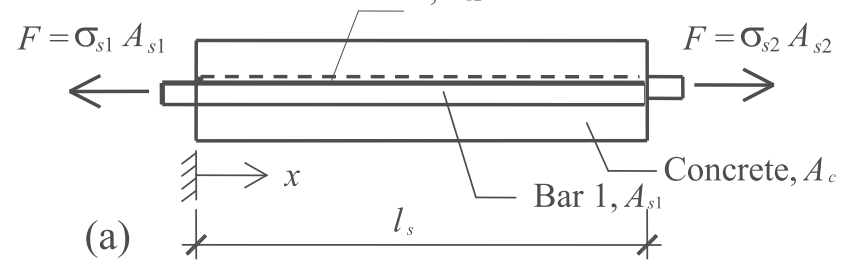

$\sigma_{c}$

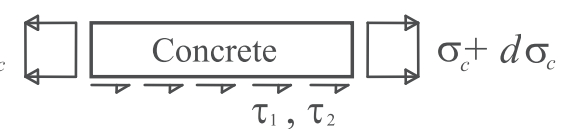

$\tau_{2}$

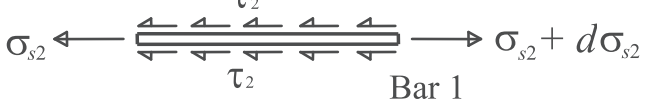

$\tau_{1}$

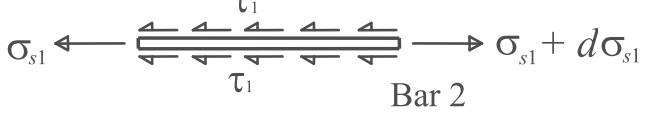

Bar 2

$\sigma_{c}$

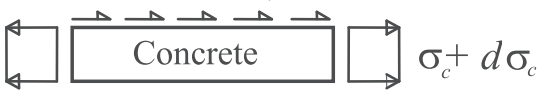

(b)

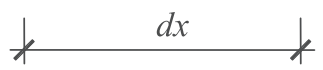

Bar 1, $A_{s 1}$

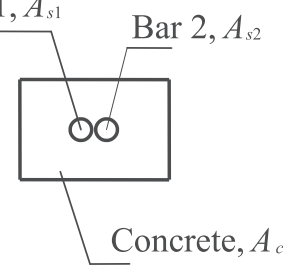

$A_{S 1}=A_{s 2}=\pi \Phi^{2} / 4$

$\rho=A_{s 1} / A_{c}=A_{s 2} / A_{c}$

Fig. 6. (a) Schematic representation of a lap splice; (b) equilibrium of stresses.

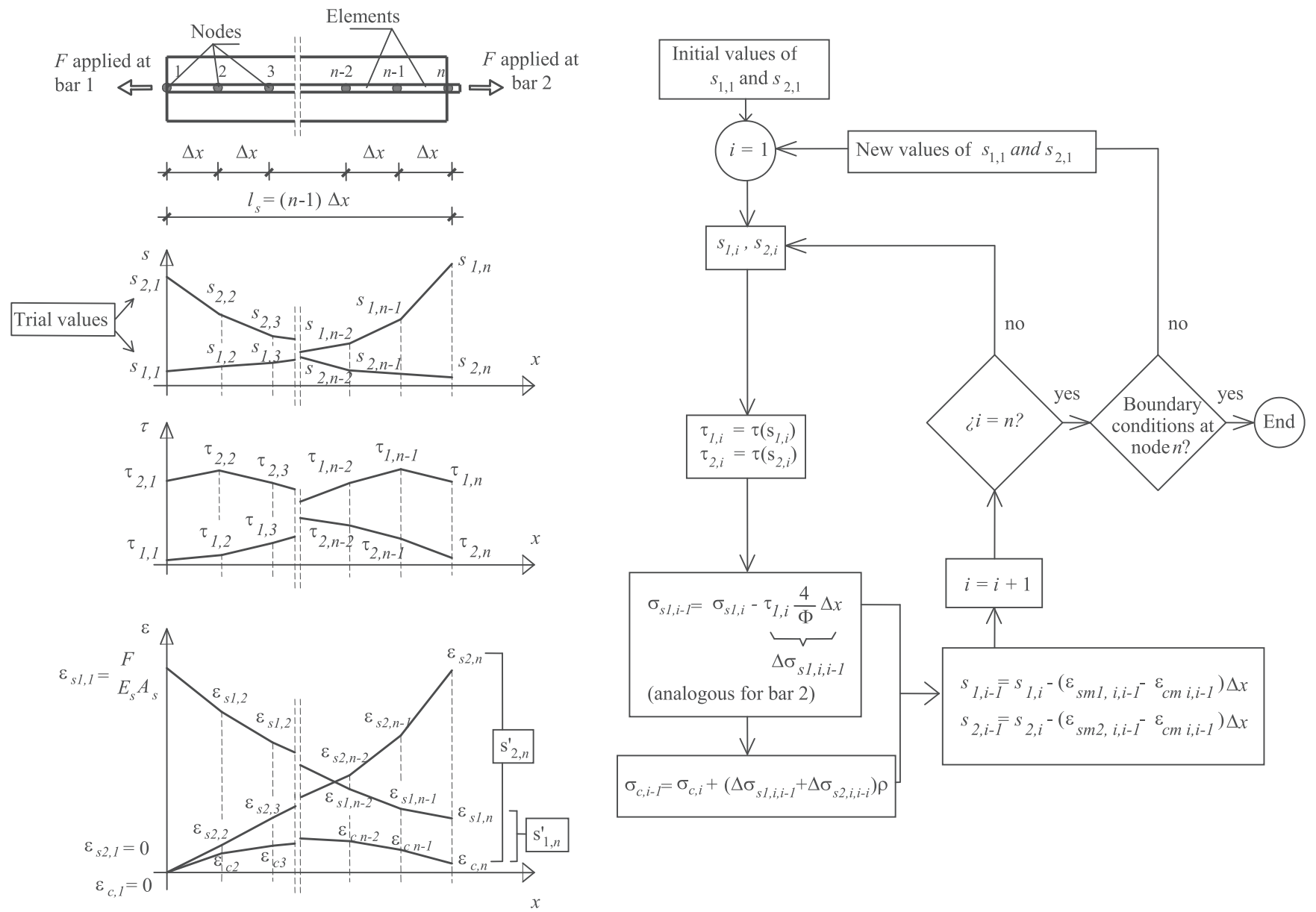

Fig. 7. Numerical algorithm to solve the lap splice. Discretization and flow chart. 


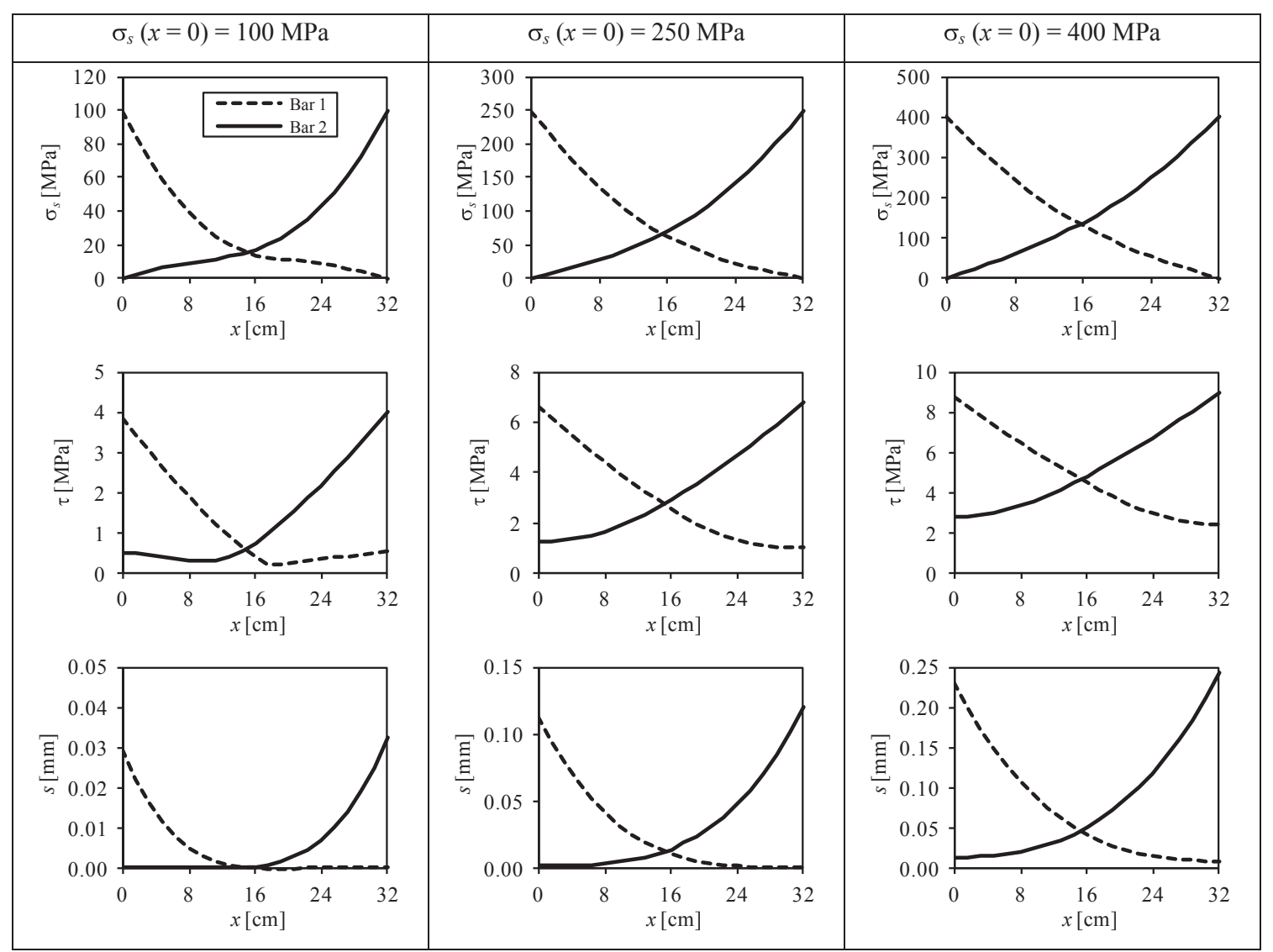

Fig. 8. Distribution of stresses and relative slips over the splice length for different load levels $\left(\Phi=16 \mathrm{~mm}, l_{s}=20 \Phi, \rho=0.03, f_{c}=40 \mathrm{MPa}\right.$, bond-slip properties assuming well-confined condition).

slipping length becomes larger and, from a certain load value, the bars slip along the whole lapped length. If the load is then increased (Fig. 8right), slips and bond stresses grow nonproportionally due to the nonlinear bond-slip behaviour and, simultaneously, the steel stress distribution of the bars straightens. The carrying capacity of the lap splice is obtained when the load applied at bar 1 cannot be transferred to bar 2 because bond stresses are not sufficient. At that instant, uniform or almost uniform bond stress distribution is obtained and steel stresses follow straight lines. In case of poor confinement, the stage of more-orless uniform stress distribution might not even be reached as the formation of a splitting crack leads to sudden bond stress drop [38]. The adoption of the appropriate bond-slip law (i.e. local confinement condition) allows the model to reproduce the corresponding failure mode by splitting or pull-out.

The model can be employed to calculate the required lapped length to splice a given load and it can be compared with the requirements of design codes. The results are presented in Fig. 9 for three different confinement conditions. As a design standard, the Eurocode 2 [10] is referred to, which has established the following equation to calculate the required lapped length of straight bars in tension with sufficient concrete cover (additional reduction factors $\alpha_{1}$ to $\alpha_{5}$ apply to Eq. (17) in other cases):

$l_{s}=\alpha_{6} l_{b, r q d} \geqslant l_{s, \min }$

$l_{s, \min }=\max \{15 \Phi ; 200 \mathrm{~mm}\}$

where $l_{b, r q d}$ is the basic required anchorage length calculated assuming a constant bond stress of $f_{b d}$ and $\alpha_{6} \geq 1.0$ is a function of the percentage of lapped reinforcement (for the common case of a percentage larger than $50 \%, \alpha_{6}=1.5$ ). According to Eurocode 2 [10], the basic anchorage length is given as: $l_{b, r q d}=\frac{\Phi}{4} \frac{\sigma_{s d}}{f_{b d}}$

$f_{b d}=2.25 \eta_{1} \eta_{2} f_{c t d}$

In Eqs. (19) and (20), $\sigma_{s d}$ is the steel stress to be anchored along $l_{b, r q d}, \eta_{1}$ takes into account the bond conditions ( 1.0 or 0.7 for good or poor conditions, respectively), $\eta_{2}$ is a reduction factor for diameters larger than $32 \mathrm{~mm}$, and $f_{\text {ctd }}$ is the design concrete tensile strength.

The comparison between the required lapped length according to the model of this paper and the Eurocode 2 is represented in Fig. 9 (safety factors have been set to 1.0). As it can be noted, the lapped length calculated with Eq. (17) is slightly larger than the one obtained with the model for unconfined concrete. If factor $\alpha_{6}$ is ignored in Eq. (17), the lapped length required by the Eurocode 2 is reduced to the anchorage length of Eq. (19), which has been represented as dotted line in Fig. 9 and it results equal to the lapped length obtained with the model under moderately confined condition. Actually, the lapped length calculated with the model presented in this paper results the same as the anchorage length obtained with an analogous model by the authors [21]. The coincidence is logical because the bond stress distribution at failure is rather uniform and it is in agreement with the fact that the main difference between the formulations of Eurocode 2 for lapped and anchorage lengths comes from factor $\alpha_{6}$. Even though a discussion on factor $\alpha_{6}$ is not the focus of this paper, it becomes apparent that the presence of $\alpha_{6}$ in the code formulation provides some additional safety for possible local bond weakness in lap splices with respect to simple anchored bars. Other codes provide even larger values for $\alpha_{6}$ (e.g. 2.0 by the Spanish code [39]), but the last version of Model Code [15] has ignored it and a commentary in section 6.1.3.7 states that "recent research demonstrates the $\alpha_{6}$ factor provided in MC90 for the proportion of bars lapped at a section to be invalid". 

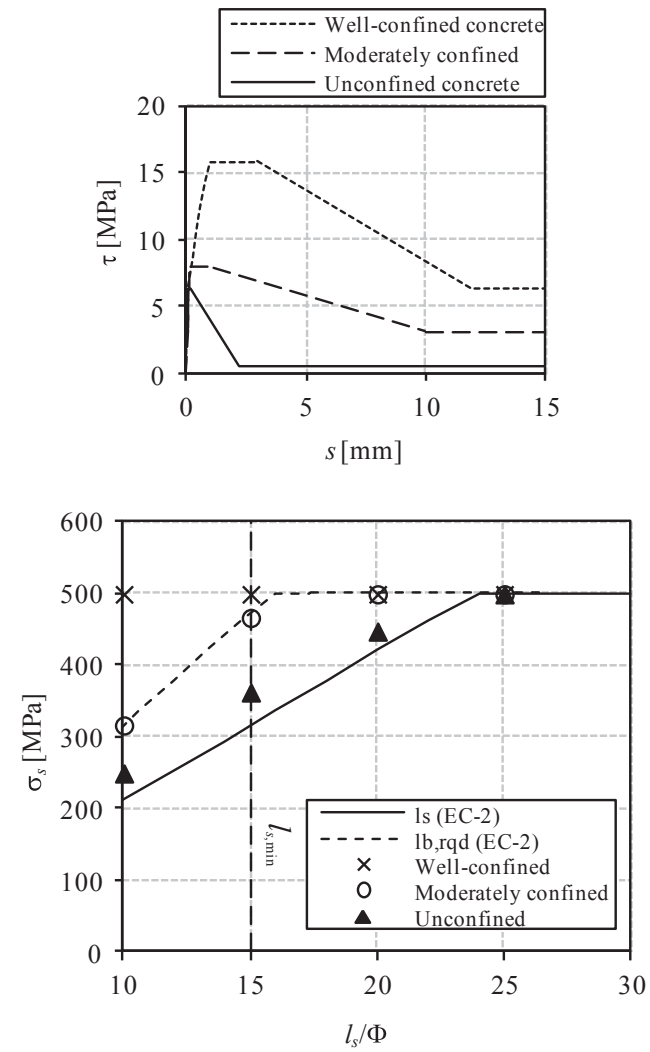

Fig. 9. Comparison of calculated splice length with the provisions of Eurocode 2 [10] for different confinement conditions $\left(\Phi=16 \mathrm{~mm}, l_{s}=20 \Phi, \rho=0.03\right.$, $f_{c}=40 \mathrm{MPa}, f_{y}=500 \mathrm{MPa}, \alpha_{6}=1.5$, safety factors $\left.=1.0\right)$.

An important capability of the model, which is fundamental to evaluate the fatigue strength (as explained in the next sections), is the derivation of the real distribution of bond stresses of the lap splice. Such a capability was already determined fundamental for anchorage of embedded bars [21]. The different stress distribution of a lap splice and an anchorage with the same length can be observed in Fig. 10 (stresses of the lap splice are plotted only for bar 1 due to symmetry with bar 2). The differences mainly come from the particular boundary conditions of both problems. From Fig. 10, it can be observed that bond stresses are rather similar for both problems at the loaded end of the bars $(x=0)$. Instead, bond stresses at the free end $(x=32 \mathrm{~cm})$ are higher in the anchorage than in the lap splice, which indicates a higher capacity for stress redistribution of lap splices with respect to comparable anchorages. This redistribution capacity plays a significant role against fatigue, as discussed in the next sections.

\section{Fatigue model for lap splices}

As demonstrated in the previous sections, each bond-related structural problem has different governing and boundary conditions, which results in nonuniform bond stress distributions. Because the bond sensitivity to repeated loading is stress-dependent (both the slip increase with load cycles and the S-N curve, Eqs. (2) and (5)), a realistic determination of bond stress distribution is crucial. Moreover, it is clear from a simple analysis of existing experimental results that a direct evaluation of fatigue strength with the S-N curve and assuming uniform bond stress is not accurate, as detailed in Fig. 11. In Fig. 11, results of fatigue tests of anchorages [22,23] and lap splices [29,37] are compared with Eq. (5). The bond stress of each test has been calculated assuming uniform distribution as follows:

$\tau_{\max }=\frac{1}{4} \frac{\sigma_{s, \max }}{l / \Phi}$ where $\sigma_{s, \max }$ is the steel stress at the loaded end under maximum load and $l$ represents either the lapped or the anchorage length. It is clear that the results from different campaigns analyzed in Fig. 11 do not follow the same trend, which is due to the different stress distribution of lap splices and anchorages. Moreover, results for lap splices with different lapped lengths also have different trend. Even though the simple evaluation of fatigue strength from the S-N curve under the assumption of uniform bond stress might provide conservative estimates, such a methodology would be too onerous. Therefore, it is justified to understand the real fatigue behaviour of bond problems. The work carried out in [21] has already addressed the behaviour of anchorages; lap splices are specifically dealt with in this paper.

According to Eq. (2), repeated loads produce increase of relative slip between steel and concrete. Because of the nonlinear stress distribution along the lapped length, the free slip increase at each point of the lap would be different. Since compatibility between concrete and steel (imposed by Eqs. (11) and (12)) has to be respected, the free slip increase cannot develop. The restrain to the free slip results in a progressive redistribution of stresses and a compatible slip increase with load cycles. The cyclic response is conceptually similar to the behaviour of a reinforced concrete in section under bending fatigue explained in Section 1 (refer also to Fig. 1).

In order to reproduce the cyclic response of a lap splice, a three-step methodology is presented here. The model structure is similar to the relaxation method for time-dependent behaviour of reinforced concrete sections [40] and it has been successfully employed for other bond problems $[21,26]$. The number of load cycles $(N)$ is considered in the model as a pseudo-time, i.e. the cyclic response is not evaluated cycleby-cycle, which would be inefficient. Accordingly, Eq. (2) can be seen

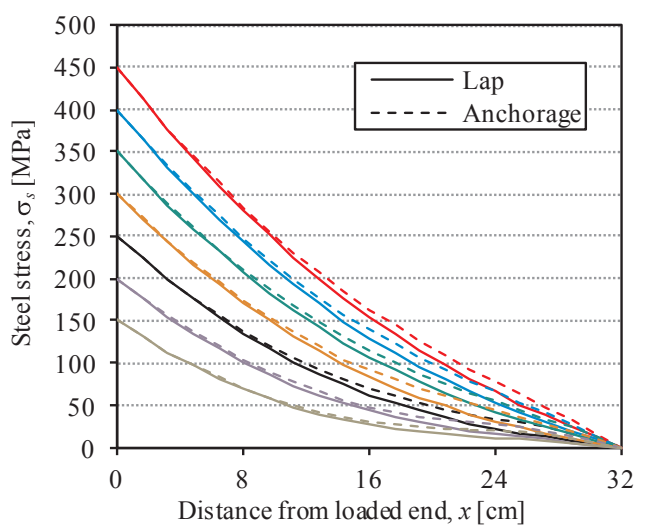

(a)

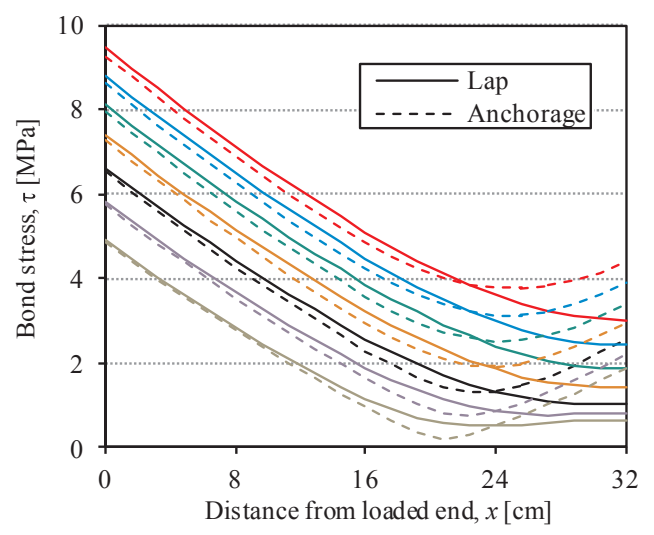

(b)

Fig. 10. Comparison of distribution of steel stress and bond stress of lap splice and anchorage for different load levels $\left(\Phi=16 \mathrm{~mm}, l_{s}=l_{b}=20 \Phi, \rho=0.03\right.$, $f_{c}=40 \mathrm{MPa}$, bond-slip properties assuming well-confined condition). 


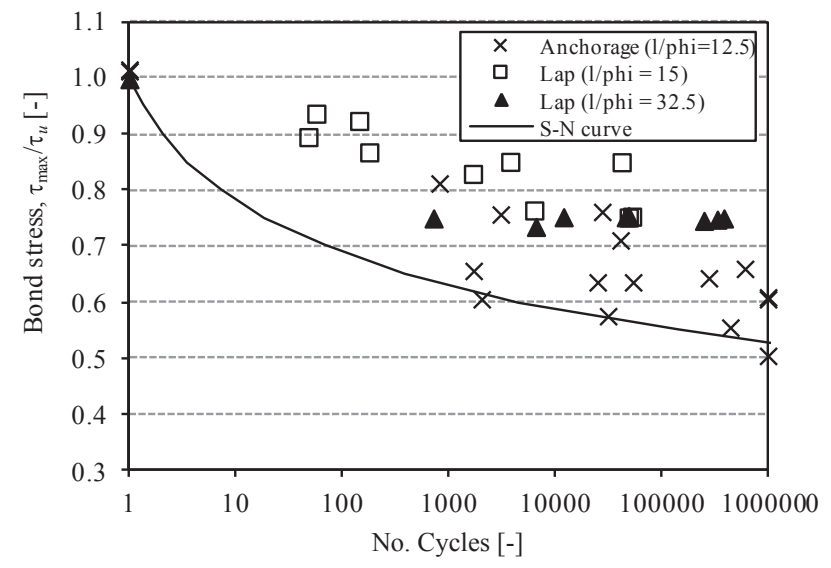

Fig. 11. Comparison of fatigue strength of experimental results of lap splices and anchorages with S-N curve and uniform bond stress distribution.

as a pseudo-creep function. The number of load cycles is divided into sets of cycles in which the stress limits are considered constant and they are those reached after the previous sets of cycles. The effect of each set of cycles is evaluated in three steps as follows.

In the first step, the free slip increase of each node of the lap splice (refer to the meaning of nodes used in Section 3.2 and Fig. 7) is calculated with Eq. (2). The stress level ( $\left.\tau_{\max }\right)$ required in Eq. (2) at each node is the one obtained after the previous sets of cycles. In the second step, the free slip increase of the first step is fully restrained with the unloading behaviour plotted in Fig. 3(b), which produces negative bond stresses at each node. After steps 1 and 2, the slip increase at each node is zero as the free slip has been fully restrained, which obviously verifies compatibility, but bond stresses have changed after the unloading process. The resulting bond stresses after steps 1 and 2 do not verify local equilibrium (Eqs. (8)-(10)) and a third step is necessary to recover equilibrium. The third step consists of the application of the bond stresses of the second step in reverse direction to the lap splice with the re-loading criterion represented in Fig. 3(b). It is noted that the reloading behaviour makes use of the reduced envelope concept [41] to introduce the bond damage caused by cyclic loads. The reduced bondslip envelope is defined by a peak slip $s_{1}$ increased according to Eq. (2). The third step is solved with the same numerical algorithm explained in Fig. 7, i.e. equilibrium and compatibility equations are respected. The result of the set of cycles is obtained by summing the results of the three steps; physically, a redistribution of stresses and a compatible increase of slip take place after the set of cycles.

An example is represented in Fig. 12(a), which corresponds to the application of 1 million load cycles to the lap splice considered in Fig. 8middle (well-confined condition). Load cycles are such that the steel stress at the loaded end oscillates between $\sigma_{s, \max }=250 \mathrm{MPa}$ and $\sigma_{s, \min }=25 \mathrm{MPa}$. Only results at bar 1 are plotted in Fig. 12 (those of bar 2 are symmetrical). The effect of the cyclic load is an increase of the relative slip between the steel and the concrete and a redistribution of stresses. The shape of bond stresses changes from a nonlinear one after the first cycle to a more uniform distribution after 1 million cycles. Due to the fatigue deterioration, a certain amount of the stresses initially transferred by the most fatigued zone near the loaded end have to be transferred by the less damaged zone near the free end. The shape of the steel stress distribution also straightens as bond stresses become more uniform along the lapped length. The same lap splice is studied in Fig. 12(b) by changing the bond condition to unconfined (bond-slip curve plotted in Fig. 9). The solution for the first load cycle is rather similar to that of Fig. 12(a) because the applied load leads to a bond stress at the loaded end $(x=0)$ of about the splitting strength, which means that a splitting crack would initiate at that end. The effect of cyclic loading is now governed by the propagation of the splitting crack, which is observed by a significant drop of bond stresses near the loaded end. Accordingly, load cycles do not lead now to a linear distribution of steel stresses, but a rather horizontal distribution is obtained near the loaded end where bond stresses are very small and, therefore, the stress transfer capacity has been decreased. This result agrees with the description reported by other authors $[38,42]$. The slip increase with load cycles is also much higher for the poorer bond condition (compare slips of Fig. 12(a) and (b)).

A fatigue failure criterion consistent with the local slip-based failure criterion of Section 2 would establish the failure instant of a lap splice as the number of cycles when the relative slip at a critical section has reached $s_{1}$. According to the evolution of the relative slip of the examples of Fig. 12, the critical slip has been reached only near the loaded end for the well-confined bond condition (Fig. 12(a)), while for the unconfined condition it has been reached along the whole lapped length. From the analysis of experimental results (refer to the next section), the failure criterion has been adopted as the number of load cycles when the critical slip $s_{1}$ is reached at the free end, i.e. when it is overcome along the whole lapped length. The example of Fig. 12(b) is, therefore, in fatigue failure situation.

\section{Comparison with tests of the literature}

\subsection{Long lap splices}

In this section, the validity of the fatigue model for lap splices is firstly studied by comparison with existing experimental results completed by Rezansoff et al. [37]. The test configuration consisted of reinforced concrete beams subjected to four-point bending, as schematized in Fig. 13(a). The tensile bars were lap-spliced in the central part of the specimens subjected to pure bending. Two long splice configurations were tested: series A $\left(l_{s}=30 \Phi\right.$ and confining stirrups spaced at $129 \mathrm{~mm})$ and series B $\left(l_{s}=32.5 \Phi\right.$ and confining stirrups spaced at
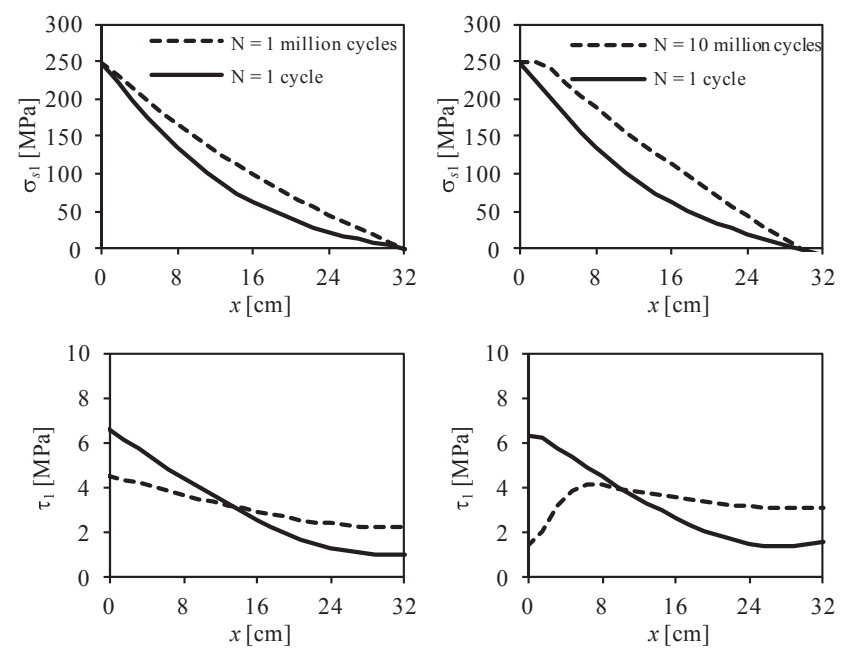

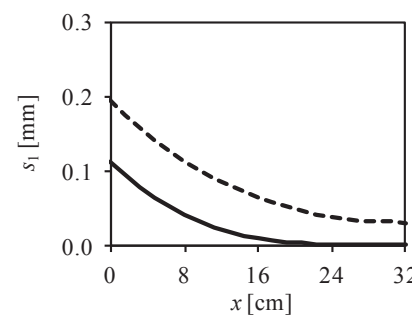

(a)

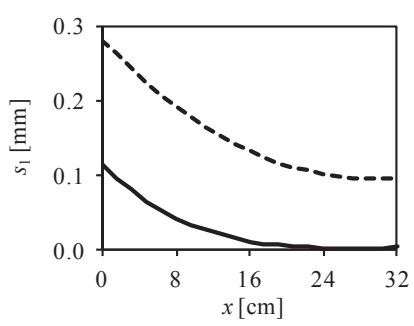

(b)
Fig. 12. Evolution of stresses and relative slips of bar 1 after cyclic loading $\left(\Phi=16 \mathrm{~mm}, \quad l_{s}=20 \Phi, \quad \rho=0.03, \quad f_{c}=40 \mathrm{MPa}, \quad \sigma_{s, \max }=250 \mathrm{MPa}\right.$, $\sigma_{s, \min }=0.1 \sigma_{s, \max }$ ). Bond-slip properties assuming: (a) well-confined condition; (b) unconfined condition. 

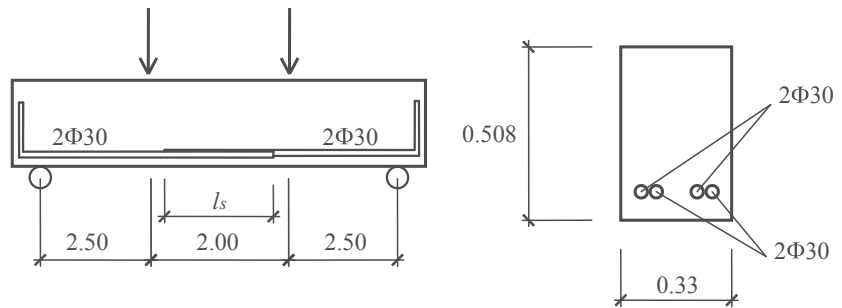

(a)

Cross-section at midspan

Concrete cover $=50 \mathrm{~mm}$

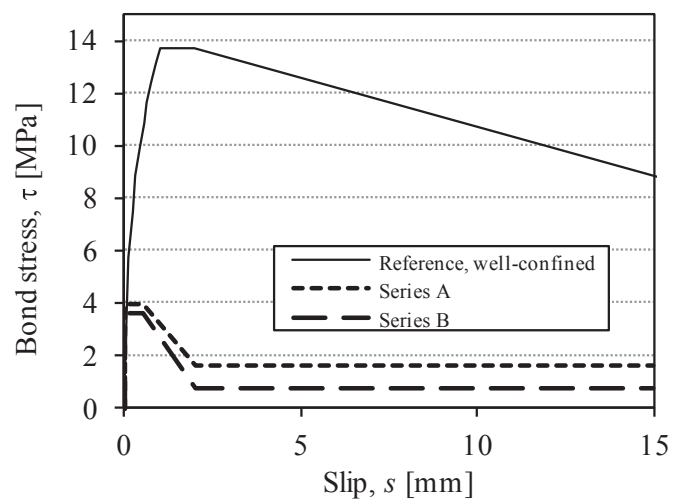

(b)

Fig. 13. (a) Configuration of tests by Rezansoff et al. [37]. (b) Adopted bondslip behaviour.

$195 \mathrm{~mm}$ ). From monotonic tests to failure, the quasi-static carrying capacity of the lap splice was $473 \mathrm{MPa}$ and $462 \mathrm{MPa}$ for series A and B, respectively, with a failure mode given by bond splitting. Fatigue tests consisted of load cycles of constant load limits. All geometric and loading details have been comprehensively reported by the original authors $[43,44]$, so they are not repeated here.

In order to reproduce the experiments with the model of this paper, the local quasi-static bond-slip behaviour is necessary. The adopted bond-slip behaviour for series A and B has been determined from analysis of the quasi-static tests and they are represented in Fig. 13(b) together with the comparable bond-slip behaviour that would correspond to well-confined concrete. As it can be observed, the bond conditions fall within the category of moderate to poor confinement. The splitting failure mode reported for the quasi-static tests confirms such confinement degree.

The resistant number of cycles of fatigue tests is studied in Fig. 14. Experimental results are plotted by points. The fatigue strength obtained with the model is represented by a continuous line, while a dashed line provides the fatigue strength of the steel reinforcement, calculated according to the specifications of the Model Code [15]. In addition, a discontinuous line has been also plotted in Fig. 14 to represent the bond fatigue strength calculated by the assumption of uniform distribution of bond stresses and the direct application of the S$\mathrm{N}$ formulation of Eq. (5).

The analysis of Fig. 14 highlights the capabilities of the model presented in this paper. Regarding series A (Fig. 14(a)), all tested specimens failed by fatigue of the steel reinforcement. Such a result is in agreement with the model. The curve providing the fatigue bond strength of the lap splice is rather horizontal and it intercepts the S-N curve of the steel reinforcement at around $\sigma_{s, \max }=360 \mathrm{MPa}$. Accordingly, the fatigue life for load levels higher than that value would be governed by bond, while load levels smaller than that stress would be steel-driven. The experimental results fit perfectly to the former conclusion. Moreover, it is apparent from Fig. 14(a) that the assumption of uniform bond stress distribution would suggest a too premature failure

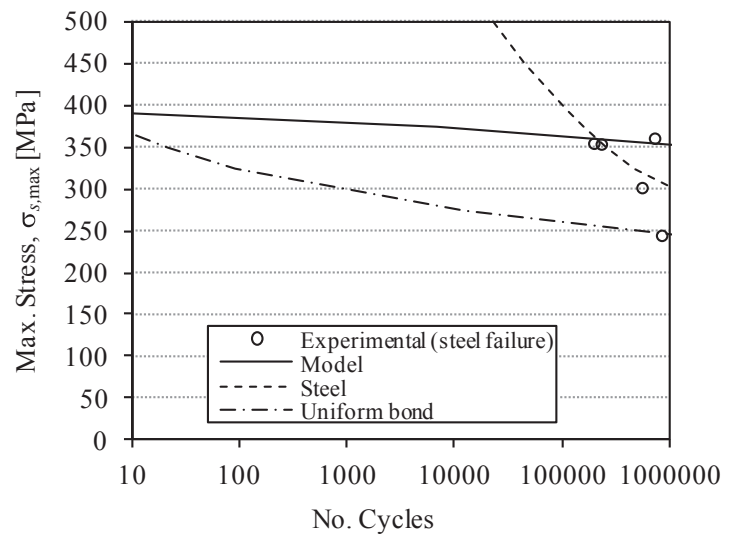

(a)

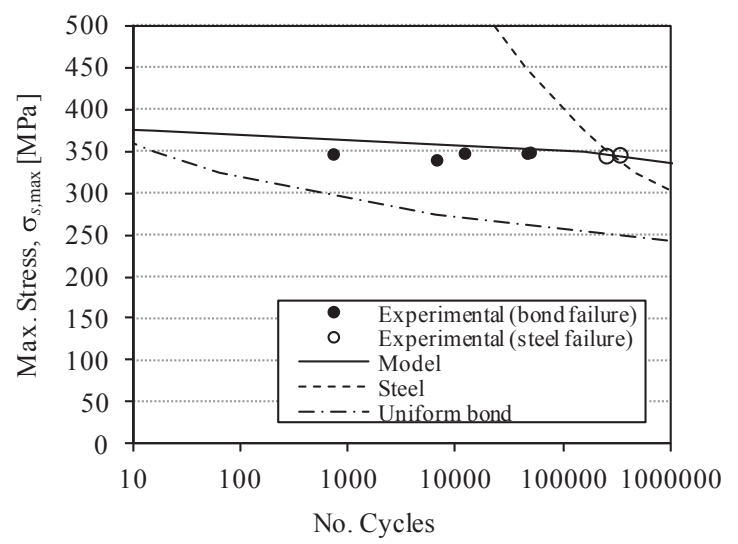

(b)

Fig. 14. Analysis of fatigue tests by Rezansoff et al. [37]: (a) Series A; (b) Series B.

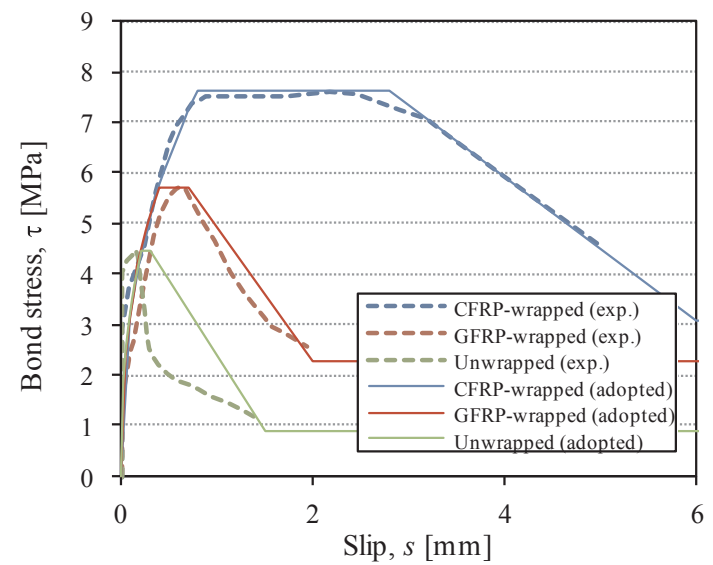

Fig. 15. Experimental bond-slip laws of tests by Alyousef et al. [29] and adopted curves adopted in the model.

by bond fatigue, which has not been obtained in the experiments. Therefore, the capacity for redistribution of stresses along the lapped length considered in the model proposed in this paper plays a determinant role.

In series B (Fig. 14(b)), many of the tests failed by fatigue of bond. The comparison between model and experimental results shows that the fatigue life can be rather well predicted by the model (like in series A, an almost horizontal curve is obtained with the model). Moreover, the distinction between failures due to fatigue of bond or fatigue of the steel is very well indicated by the interception between the curve of the 


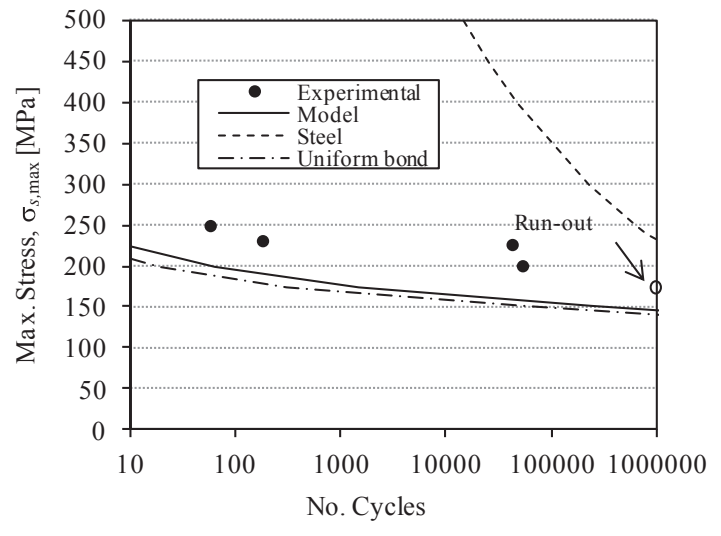

(a)

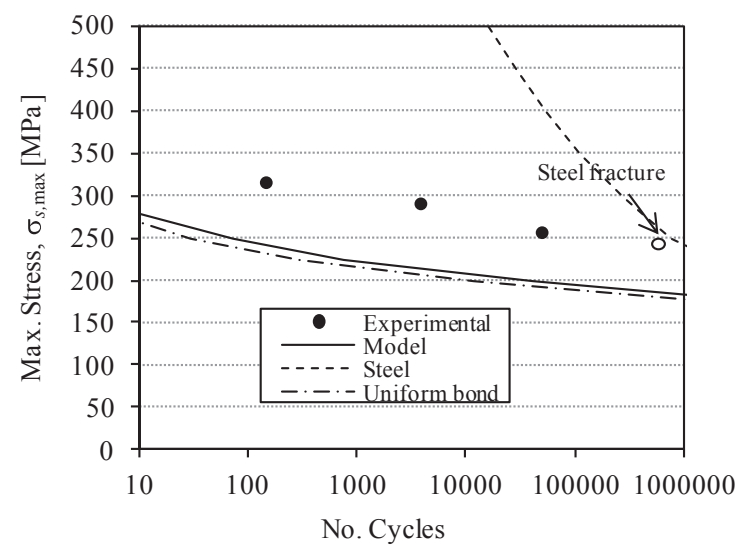

(b)

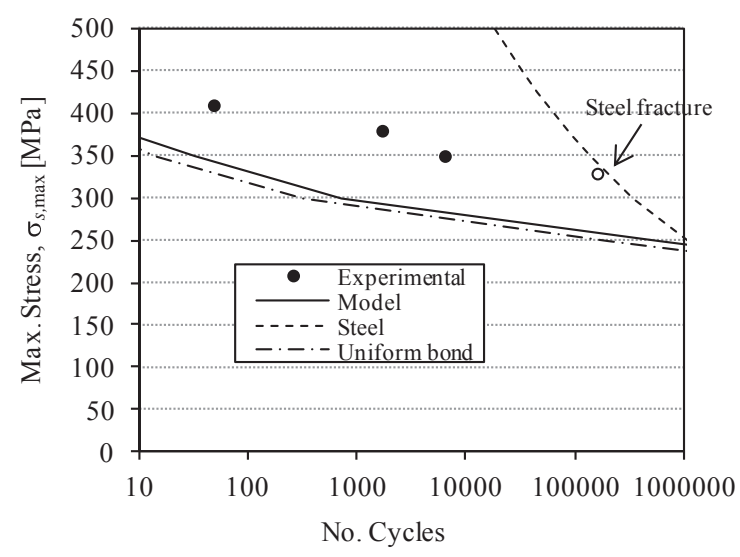

(c)

Fig. 16. Analysis of fatigue strength of tests by Alyousef et al. [29]: (a) Series U; (b) Series G; (c) Series C.

model and the S-N curve of the steel. Similarly to the analysis of series A, the assumption of uniform bond stress would produce an overconservative estimation of the fatigue strength.

It has to be noted that the resistant number of cycles obtained with the model has been established as the instant when the slip $s_{1}$ is reached at the free end of the lapped bars. If the failure criterion were established at the loaded end, the fatigue life would be much shorter and it would not match with experimental results. The physical meaning behind the established failure criterion is that bond fatigue of a lap splice takes place when the steel bars have slipped $s_{1}$ along the whole lapped length, i.e. a splitting crack has fully developed along the lap splice.

\subsection{Short lap splices}

The influence of a shorter lapped length on the fatigue performance of lap splices can be analyzed by studying the experiments recently carried out at the University of Waterloo, ON, Canada [29]. A fourpoint bending configuration rather similar to the one represented in Fig. 13(a) was employed and, therefore, it is not reproduced here for the sake of concision. The lapped length was $l_{s}=15 \Phi$, which is around the minimum required length of the codes (refer to Section 3.2). The diameter of steel bars was $20 \mathrm{~mm}$ and the clear concrete cover was also $20 \mathrm{~mm}$. Due to the small concrete-to-diameter ratio, a high sensitivity to splitting bond failure would be expected, as it was experimentally obtained in the quasi-static reference tests. The authors of the tests investigated the beneficial effect of FRP wrapping over the spliced zone: besides a series of unwrapped specimens (series U), specimens with glass-FRP (series G) and carbon-FRP (series C) wraps were also tested. The positive effect of the wraps on the bond condition of the lap splices can be observed from the quasi-static bond-slip curves provided by the authors of the tests for each series (Fig. 15). The results of fatigue tests also demonstrated significantly higher fatigue strength of wrapped specimens, in correspondence with the improved bond condition of series $\mathrm{G}$ and $\mathrm{C}$ with respect to series $\mathrm{U}$. Further details of the tests can be found in $[29,45]$. Next, the fatigue behaviour is analyzed with the model proposed in this paper.

The bond-slip laws adopted in the model for each series are plotted in Fig. 15. It is apparent that quasi-static bond failure changes from splitting (series U) to pull-out (series C). The consequences on the fatigue performance are studied in Fig. 16, where the fatigue strength of the tests is compared with the one obtained with the model (continuous line). As it can be noted, the model can predict the beneficial effect of the FRP wrapping, as the fatigue strength of the model increases from series $\mathrm{U}$ to series $\mathrm{G}$ and, further, to series $\mathrm{C}$ in a similar manner as the experimental trend. Nevertheless, the fatigue life provide by the model is some more conservative for these tests than for those analyzed in Section 5.1, especially for series G and C (Fig. 16(b) and (c)). From the authors' viewpoint, this is believed to be due to the additional influence provided of the FRP wrap on the behaviour of the lap splice, as the wraps do not only affect the steel-concrete bond conditions, but they also carry a part of the load and, actually, the interaction of the different members of the FRP-concrete-steel system should affect the equilibrium, compatibility and boundary Eqs. (8)-(16). Since such a detailed modelling of the wrapping effect is not the aim of this paper, the prediction of the fatigue strength can be considered safe and good enough, as the model is able to explain the improvement of bond condition and fatigue performance.

In the graphics of Fig. 16, the fatigue life obtained under the assumption of uniform bond stress distribution has been also represented (discontinuous lines). In contrast with the results obtained for long lap splices (Section 5.1, Fig. 14), the difference between the results of the model and those under the uniform bond stress assumption is not very large, which indicates a much smaller capacity for redistribution of a short splice length of $15 \Phi$. Such a result indicates that the redistribution capacity is larger for longer lap splices.

\section{Conclusions}

In the present paper, a model to analyze the fatigue strength of lap splices has been reported. In the first part of the paper, a local S-N formulation for fatigue of bond has been presented, which can be considered as a material property of the steel-concrete interface. The S$\mathrm{N}$ formulation is compatible with the format of the cyclic slip increase adopted by the Model Code [15]. In the second part of the paper, a numerical model has been presented to understand the real stress distribution along the lapped length. The model has allowed concluding that bond stresses do not follow a uniform distribution and, moreover, each bond-related structural problem (e.g. lap splices or anchorages) 
has a different solution regarding the stress distribution. The proposed model has allowed a discussion regarding the capabilities of the formulation of the Eurocode 2 [10] on the required lapped length and the role played by the $\alpha_{6}$ factor. Finally, the third part of the paper has dealt with the fatigue behaviour of lap splices. A cycle-dependent model has been proposed which is able to reproduce the process of redistribution of stresses produced by fatigue loading. The model allows concluding that the fatigue strength of lap splices is strongly influenced by the redistribution capacity, which in turn depends on the lapped length. From the analysis of experiments of the literature with the proposed model, it has been shown that the fatigue life of long lap splices $\left(l_{s} / \Phi=30-32.5\right)$ is significantly larger than that calculated by assuming uniform bond stress distribution. On the contrary, the study has indicated that short lap splices $\left(l_{s} / \Phi=15\right)$ have a smaller redistribution capacity. Therefore, it can be concluded that the use of a cycle-dependent model based on the real bond stress distribution is necessary in order to simulate correctly the fatigue strength of lap splices.

The analysis of experimental results has also shown that the fatigue strength of a lap splice can be governed by bond or steel failures as a function of the maximum applied stress level. Since fatigue of bond is very sensitive to the relative maximum stress, an improvement of the confinement conditions of lap splices would increase the quasi-static bond strength, thereby reducing relative stresses and enlarging the fatigue life.

\section{References}

[1] CEB. Bulletin No. 188. Fatigue of concrete structures. State-of-the-art report. Lausanne, Switzerland: CEB; 1988.

[2] Schläfli M, Brühwiler E. Fatigue of existing reinforced concrete bridge deck slabs. Eng Struct 1998;20:991-8.

[3] Johansson U. Fatigue tests and analysis of reinforced concrete bridge deck models; 2004.

[4] Thandavamoorthy TS. Static and fatigue of high-ductility bars reinforced concrete beams. J Mater Civ Eng 1999;11:41-50.

[5] Miner MA. Cumulative damage in fatigue. J Appl Mech 1945;67:159-64.

[6] Bennet EW, Raju NK. Cumulative fatigue damage of plain concrete in compression; 1969. p. 1089-101.

[7] Hsu TTC. Fatigue of plain concrete. ACI J Proc 1981;78:292-305.

[8] Holmen JO. Fatigue of concrete by constant and variable amplitude loading. Fatigue Concr Struct 1982;ACI SP-75:71-110.

[9] CEB-FIP. Model Code for concrete structures; 1991.

[10] CEN. Eurocode 2 EN 1992-1-1:2012. 2012. Design of concrete structures - Part 1: general rules and rules for buildings. Brussels; 2012.

[11] Hilsdorf HK, Kesler CE. Fatigue strength of concrete under varying flexural stresses. Aci J Proc 1966:63:1059-76.

[12] Pfister T. Ermüdungsschädigung in Stahlbetonbauteilen. Beton und Stahlbetonbau 2005; 100:165-8.

[13] Zanuy C, Albajar L, De la Fuente P. Sectional analysis of concrete structures under fatigue loading. ACI Struct J 2009;106:667-77.

[14] Ople FS, Hulsbos CL. Probable fatigue life of plain concrete with stress gradient. ACI J Proc 1966;63:59-82.
[15] FIB. Model Code for concrete structures 2010; 2013.

[16] American Concrete Institute. ACI 318-11: building code requirements for structural concrete and commentary. Framington Hills, MI: American Concrete Institute; 2011.

[17] Van Bogaert P. Fatigue due to concrete in compression in bridges compared to practice. In: FIB international symposium; 2009 [Pen drive].

[18] Balazs GL. Fatigue of bond. ACI Mater J 1992;88:620-30.

[19] Koch R, Balazs GL. Limit states for long term and cyclic loading 2002;211-21.

[20] Rehm G, Eligehausen R. Bond of ribbed bars under high cycle repeated loads. ACI J 1979;76:297-309.

[21] Zanuy C, Albajar L, De la Fuente P. Evaluation of fatigue bond strength of anchorage zones with a mechanical model. J Struct Eng 2013;139:28-38.

[22] Rteil A, Soudki K, Topper T. Mechanics of bond under repeated loading. Constr Build Mater 2011;25:2822-7.

[23] Rteil A, Soudki K, Topper T. Preliminary experimental investigation of the fatigue bond behavior of CFRP confined RC beams. Constr Build Mater 2007;21:746-55.

[24] Perry ES, Jundi N. Pullout bond stress distribution under static and dynamic repeated loadings. ACI J Proc 1969;66:377-80.

[25] Det Norske Veritas. DNV-OS-C502. Offshore concrete structures; 2010.

[26] Zanuy C. Investigating the negative tension stiffening effect of reinforced concrete. Struct Eng Mech 2010;34:189-211.

[27] American Concrete Institute. ACI 408.2R-12. Report on bond of steel reinforcing bars under cyclic loads. Farmington Hills, MI: ACI; 2012.

[28] Tepfers R, Kutii T. fatigue strength of plain, ordinary and lightweight concrete. ACI J Proc 1979;76:635-52.

[29] Alyousef R, Topper T, Al-Mayah A. Fatigue bond stress-slip behavior of lap splices in the reinforcement of unwrapped and FRP-wrapped concrete beams. J Compos Constr 2016;20:04016039.

[30] Sippel T. Zum Trag- und Verformungsverhalten von Stahlbetontragwerken unter Betriebsbelastung; 1996

[31] Zanuy C, Albajar L, De la Fuente P. On the cracking behaviour of the reinforced concrete tension chord under repeated loading. Mater Struct 2010;43:611-32.

[32] Lindorf A, Curbach M. S-N curves for fatigue of bond in reinforced concrete structures under transverse tension. Eng Struct 2010:32:3068-74.

[33] Lindorf A. Ermüdung des Verbundes von Stahlbeton unter Querzug; 2011.

[34] Zanuy C, Curbach M, Lindorf A. Finite element study of bond strength between concrete and reinforcement under uneven confinement condition. Struct Concr 2013;14:260-70

[35] Guizani L, Chaallal O. An experimental study on bond-slip in moderately confined concrete subjected to monotonic and cyclic model using an experimental plan. Can J Civ Eng 2011;38:272-82.

[36] FIB. Bulletin No. 10. Bond of reinforcement in concrete. State-of-the-art report. Lausanne, Switzerland: FIB; 2000.

[37] Rezansoff T, Zacaruk JA, Afseth JG. High cycle (fatigue) resistance of reinforced concrete beams with lap splices. Can J Civ Eng 1993;20:642-9.

[38] Tepfers R, De Lorenzis L. Bond of FRP reinforcement in concrete: a challenge. Mech Compos Mater 2003;39:315-28.

[39] Spanish Ministry for public works. Spanish code for structural concrete; 2008

[40] Ghali A, Favre R. Concrete structures: stresses and deformations. London, UK: SPON Press; 1994.

[41] Pochanart S, Harmon T. Bons-slip model for generalized excitations including fatigue. ACI Mater J 1989;86:465-76.

[42] Wahab N, Topper T, Soudki KA. Modelling experimental bond fatigue failures o concrete beams strengthened with NSM CFRP rods. Compos B 2015;70:113-21.

[43] Afseth JG. High cycle (fatigue) resistance of reinforced concrete beams with lap splices; 1993.

[44] Zacaruk JA. Performance of large size reinforced concrete beams containing a lap splice subjected to fatigue loads; 1990.

[45] Alyousef $R$. The fatigue behaviour of tension lap spliced reinforced concrete beams strengthened with Fibre Reinforced Polymer wrapping; 2016. 